\title{
ARTICLE
}

\section{Trilepisium madagascariense fruit-wastes as cheap feedstock for bioethanol production}

\author{
Ademakinwa Adedeji Nelson ${ }^{1,3^{*}}$, Agunbiade Mayowa Oladele ${ }^{2}$, Agboola Femi Kayode ${ }^{3}$ \\ ${ }^{1}$ Department of Physical and Chemical Sciences, Elizade University, Ilara-Mokin, Nigeria \\ ${ }^{2}$ Biocatalysis and Technical Biology Research Group, Institute of Biomedical and Microbial Biotechnology, Cape \\ Peninsula University of Technology, South Africa \\ ${ }^{3}$ Department of Biochemistry and Molecular Biology, Obafemi Awolowo University, Ile-Ife, Nigeria
}

\begin{abstract}
Trilepisium madagascariense fruits are carbohydrate-rich and this study directly fermented the fruit wastes into bioethanol without the need for nutrient supplementation. The total reducing sugar (TRS) present in the mesocarp and seed of $T$. madagascariense fruit wastes (Tmfw) was fermented to bioethanol using Aureobasidium pullulans. Bioethanol production by $A$. pullulans was also optimized using Box-Behnken response surface methodology (RSM). The TRS in the mesocarp and seed of Tmfw were $11.2 \pm 0.8$ and $17.1 \pm 1.2 \mathrm{~g} / \mathrm{L}$, respectively and further hydrolysis with cellulase resulted in increased TRS indicating the presence of cellulose. Pre-optimization, the bioethanol yield $\left(\mathrm{Y}_{\mathrm{ps}}\right)$ and volumetric productivity $\left(\mathrm{Q}_{\mathrm{p}}\right)$ obtained from the fermentation of the seed by $A$. pullulans were $0.57 \pm 0.03 \mathrm{~g} / \mathrm{g}$ and $0.21 \pm 0.02 \mathrm{~g} / \mathrm{L}^{-1} \mathrm{~h}^{-1}$, respectively. The optimum conditions for maximum bioethanol production were $\mathrm{pH}$ (5.95), time (24 h) and substrate concentration $(5 \mathrm{~g} / \mathrm{L})$ resulting in $Y_{p s}, Q_{p}$ of $0.66 \pm 0.06 \mathrm{~g} / \mathrm{g}$ and $0.27+0.01 \mathrm{~g} / \mathrm{L}^{-1} \mathrm{~h}^{-1}$, respectively after model validation. Tmfw served as a suitable, cheap, non-toxic and readily available substrate especially in Nigeria to produce bioethanol while A. pullulans is a fungus that might be utilized for large-scale industrial bioethanol production.
\end{abstract}

Acta Biol Szeged 63(1):45-50 (2019)

\section{KEY WORDS}

Aureobasidium pullulans

bioethanol

submerged fermentation

Trilepisium madagascariense

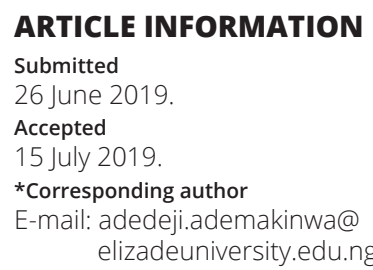

\section{Introduction}

Bioethanol is produced by microbial fermentation of plants containing sugar, starch and lignocellulosic materials (Joshi et al. 2012). In contrast to ethanol, bioethanol can be obtained from biomass-based waste materials or other renewable sources such as high sugar-containing plant materials (Dash 2017). It can be used as fuel, chemical feedstock and as a solvent in various industrial processes (Alma et al. 2015).

Bioethanol is referred to as a sustainable alternative energy source, which is both renewable and environmentally acceptable (Lebaka 2013). It is by far most widely used in transportation and it is oxygenated, thereby provides the potential to reduce particulate emissions in compression ignition engines (Razmovski et al. 2012). A variety of plant materials has been used for the first, second and third generation bioethanol production. The first-generation bioethanol production involves plant materials rich in sucrose (sugarcane, sugar beet, sweet sorghum, and fruits) and starch (corn, wheat, rice, potato, cassava, sweet potato and barley). The sugar-based ethanol is predominantly produced from sugarcanes while starch-based ethanol is mainly from corn but also from grains. The production of first-generation ethanol poses a low risk and does not require harsh pretreatment of the substrate. However, the utilization of edible agricultural crops solely for biofuel production conflicts with food and feed production (Sharma and Sharma 2018). The focus of this study is, therefore, to exploit the under-utilized Trilepisium madagascariense fruit wastes for the possible production of bioethanol since these seeds have been reported to be rich in carbohydrates (60\%) (Adewuyi et al. 2010). Several reports exist that shows the plant has medicinal values as it is applied in the treatment of some ailments mostly because of its rich antioxidant/phytochemical properties (Nwamarah et al. 2015). These fruit wastes, therefore, could serve as a source of bioethanol production in certain countries (e.g., Nigeria) because it is cheap, costeffective and readily available. The cost-effectiveness of bioethanol production is highlighted in this study since the process of production of this biofuel is free of enzymatic hydrolysis which is hitherto expensive. The economics of bioethanol production is greatly influenced by the cost of the feedstock, which accounts for more than half of the production costs. Hence, utilizing the cheap waste of the ripened fruits of T. madagascariense which is rich in 
reducing sugars is exploitable for large-scale production of bioethanol locally in countries like Nigeria.

In this study, there was a determined effort to investigate if Aureobasidium pullulans can hitherto ferment reducing sugars present in the T. madagascariense into ethanol anaerobically. A. pullulans have been reported to contain enzymes that can hydrolyze sucrose to produce glucose and sucrose e.g., invertases and fructosyltransferases (Ademakinwa et al. 2017). This will offer a new fungusbased method for large scale production of bioethanol in countries where T. madagascariense available.

\section{Materials and Methods}

\section{Reagents}

Trichoderma reesi cellulase, dinitrosalicyclic acid, sodiumpotassium-tartrate, sodium hydroxide, glucose, carboxymethyl cellulose, sodium acetate, ethanol, sodium dichromate dihydrate, sulphuric acid and glacial acetic acid were of analytical grade and purchased from SigmaAldrich (USA).

\section{Microorganisms and culture conditions}

The industrial strain of S. cerevisiae was obtained from the Department of Chemical Engineering, Obafemi Awolowo University, Ile-Ife, Nigeria. A. pullulans were previously isolated from soil containing decayed plant litters and its molecular identification was based on sequencing of the ITS1-ITS4 genomic region (Ademakinwa and Agboola 2016). Both fungi were maintained on malt extract agar (MEA) for 96 hours at $4{ }^{\circ} \mathrm{C}$ on agar slants. Preparation of the inoculum and growth medium were as described by Ademakinwa et al. (2017). All the yeast was incubated anaerobically in an anaerobic jar during ethanol production.

\section{Preparation of T. madagascariense seeds and mesocarp}

Ripened fruits wastes were collected from the base of the T. madagascariense trees located in the Botanical Garden, Obafemi Awolowo University, Ile-Ife. The fruit wastes were then washed in sterile distilled water. The mesocarps were carefully separated from the seeds using a sterile razor blade and homogenized separately in distilled water $(1: 2) \mathrm{w} / \mathrm{v}$. The homogenate was then clarified by centrifugation at $4000 \mathrm{~g}$ for $20 \mathrm{~min}$. The supernatant was stored at $4{ }^{\circ} \mathrm{C}$ prior to further use. The total reducing sugars present were quantified using the dinitrosalicyclic acid method described by Miller (1959) with glucose as standard.

\section{Enzymatic treatment of the homogenate}

The supernatant obtained after centrifugation was investigated for possible increased release of more reduc- ing sugar by hydrolysis of the cellulose present in the mesocarp and seeds. Cellulase assay was carried out according to methods described by Quadri et al. (2017) using 3,5 dinitrosalicyclic acid (Miller 1959). Cellulase $(0.1-10 \% \mathrm{w} / \mathrm{v})$ was added to the clarified homogenate for the hydrolysis of cellulose present in the seeds and mesocarp. The reducing sugars released were quantified as described above.

\section{Fermentation and conditions}

The clarified supernatant served as the medium for fermentation and it was fermented by $A$. pullulans and $S$. cerevisiae in $100 \mathrm{ml}$ Erlenmeyer flasks that contained 20 $\mathrm{ml}$ of the clarified supernatant in an anaerobic jar. The medium for fermentation was inoculated with $1 \%(\mathrm{v} / \mathrm{v})$ fungal cultures as inoculum. The effects fermentation time on reducing sugar consumption and ethanol production were determined. After every $24 \mathrm{~h}, 2 \mathrm{ml}$ was aseptically withdrawn, centrifuged at $4000 \mathrm{~g}$ for $10 \mathrm{~min}$ and the ethanol and reducing sugar present in the supernatant were quantified. The ethanol yield and productivity were calculated using the Equation 1.:

$$
\underset{\mathrm{Y}_{(\mathrm{p}, \mathrm{s})},(\mathrm{g} / \mathrm{g})}{\text { Ethanol yield }}=\frac{\text { Ethanol Produced }(\mathrm{g} / \mathrm{L})}{\text { Sugar consumed }(\mathrm{g} / \mathrm{L})}
$$

$\begin{gathered}\text { Volumetric productivity } \\ \mathrm{Q}_{\mathrm{p}}(\mathrm{g} / \mathrm{L} \times \mathrm{h})\end{gathered}=\frac{\text { Ethanol Produced }(\mathrm{g} / \mathrm{L})}{\text { Fermentation time }(\mathrm{h})}$

\section{Analytical processes}

Ethanol was quantified using the dichromate method described by Hormitz (1980) as modified by Betiku et al. (2015). The reducing sugar was quantified using the dinitrosalicyclic method described by Miller (1959).

\section{Optimization of the bioethanol production processes}

Response surface methodology (RSM) was used to optimize the bioethanol production process from the seed of T. madagascariense and to investigate the influence of different fermentation process variables on the bioethanol yield. The variables considered are $\mathrm{pH}$, fermentation time (h) and substrate concentration $(\mathrm{g} / \mathrm{L})$. To evaluate the effect of initial $\mathrm{pH}$, the medium for fermentation

Table 1. Process parameters for Box-Behnken response surface methodology.

\begin{tabular}{llll}
\hline Variable & \multicolumn{3}{c}{ Coded factor levels } \\
\hline & -1 & 0 & +1 \\
$\mathrm{pH}$ & 4.95 & 5.95 & 6.95 \\
Substrate concentration (g/L) & 5 & 7.5 & 10 \\
Time (h) & 24 & 36 & 48 \\
\hline
\end{tabular}


Table 2. Experimental runs for the Box-Behnken design for ethanol optimization.

\begin{tabular}{llllll}
\hline Runs & pH & $\begin{array}{l}\text { Substrate } \\
(\mathbf{g} / \mathbf{L})\end{array}$ & $\begin{array}{l}\text { Time } \\
(\mathbf{h})\end{array}$ & \multicolumn{2}{c}{ Bioethanol yield (Yps) (g/g) } \\
\cline { 5 - 6 } & & & & $\begin{array}{l}\text { Experimental } \\
\text { value }\end{array}$ & $\begin{array}{l}\text { Predicted } \\
\text { value }\end{array}$ \\
\hline 1 & $4.95(-1)$ & $2.5(-1)$ & $36(0)$ & 0.53 & 0.53 \\
2 & $6.95(+1)$ & $2.5(-1)$ & $36(0)$ & 0.57 & 0.57 \\
3 & $4.95(-1)$ & $7.5(+1)$ & $36(0)$ & 0.53 & 0.53 \\
4 & $6.95(+1)$ & $7.5(+1)$ & $36(0)$ & 0.57 & 0.57 \\
5 & $4.95(-1)$ & $5.0(0)$ & $24(-1)$ & 0.56 & 0.56 \\
6 & $6.95(+1)$ & $5.0(0)$ & $24(-1)$ & 0.54 & 0.54 \\
7 & $4.95(-1)$ & $5.0(0)$ & $48(+1)$ & 0.48 & 0.48 \\
8 & $6.95(+1)$ & $5.0(0)$ & $48(+1)$ & 0.59 & 0.59 \\
9 & $5.95(0)$ & $2.5(-1)$ & $24(-1)$ & 0.53 & 0.53 \\
10 & $5.95(0)$ & $7.5(+1)$ & $24(-1)$ & 0.53 & 0.53 \\
11 & $5.95(0)$ & $2.5(-1)$ & $48(+1)$ & 0.52 & 0.52 \\
12 & $5.95(0)$ & $7.5(+1)$ & $48(+1)$ & 0.51 & 0.51 \\
13 & $5.95(0)$ & $5.0(0)$ & $36(0)$ & 0.63 & 0.63 \\
14 & $5.95(0)$ & $5.0(0)$ & $36(0)$ & 0.64 & 0.63 \\
15 & $5.95(0)$ & $5.0(0)$ & $36(0)$ & 0.63 & 0.63 \\
16 & $5.95(0)$ & $5.0(0)$ & $36(0)$ & 0.64 & 0.63 \\
17 & $5.95(0)$ & $5.0(0)$ & $36(0)$ & 0.63 & 0.63 \\
\hline
\end{tabular}

was subjected to $\mathrm{pH} 4.95,5.95$, and 6.95 using $1 \mathrm{~N} \mathrm{NaOH}$ and $\mathrm{HCl}$, respectively. The Box-Behnken method was selected for the optimization of ethanol concentration. All variables were set at a central coded value of zero. The minimum and maximum ranges used in this optimization were selected based on, the basis of previous one-factor at-a-time independent study. The variables, factors, and levels are referenced in Table 1 . Seventeen individual runs were conducted for the three independent variables (Table 2) for the quantification of ethanol. Ethanol yield was analyzed by using a second-order polynomial equation and data-fitting by multiple regression techniques using Design-Expert (version 6.0, Stat-Ease, Minneapolis, USA). The model equation for analysis is given in Equation 2.:

$$
\begin{gathered}
\alpha=\mu \mathrm{o}+\mu_{1} Z_{1}+\mu_{2} Z_{2}+\mu_{3} Z_{3}+\mu_{12} Z_{1} Z_{2}+\mu_{13} Z_{1} Z_{3}+\mu_{23} Z_{2} Z_{3}+ \\
\mu_{11} Z_{12}+\mu_{22} Z_{22}+\mu_{33} Z_{32}
\end{gathered}
$$

Where the predicted response (Bioethanol yield $\mathrm{g} / \mathrm{g}$ ) is denoted by $\alpha, \mu o$ is the model constant, $Z_{1}, Z_{2}$ and $Z_{3}$ are independent variables, $\mu_{1}, \mu_{2}$ and $\mu_{3}$ are linear coefficients, $\mu_{12}, \mu_{13}$ and $\mu_{23}$ are cross product coefficients and $\mu_{11}, \mu_{22}$ and $\mu_{33}$ are the quadratic coefficients representing the constant process effect in total. The linear $\left(\alpha_{\mathrm{i}}\right)$, quadratic effect $\left(\alpha_{j}\right)$ and the interaction effect between $\alpha_{i}$ and $\alpha_{j}$ for the production. The experimental/predicted values and the response surface plots were compared to determine the optimum conditions for bioethanol production.

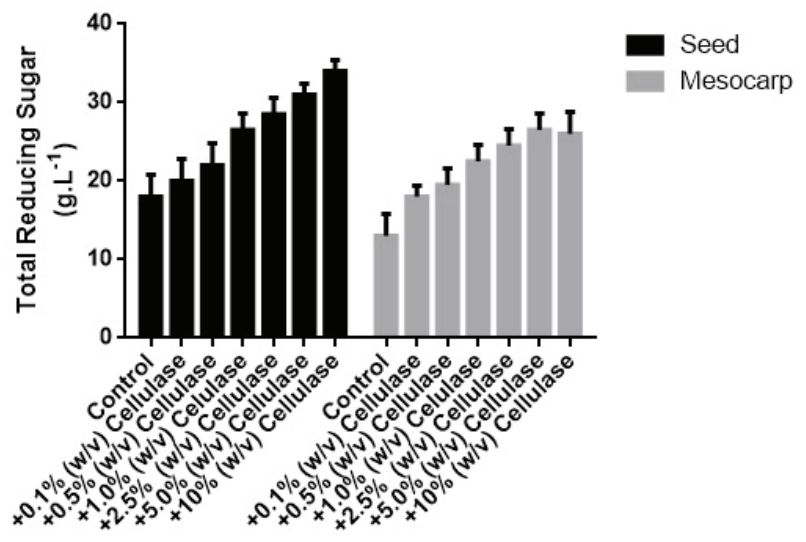

Figure 1. Total reducing sugars present in the seed and mesocarp of $T$. madagascariense fruit waste ( $T m \mathrm{Fw})$ with and without cellulase $(0.1-10 \%$ $\mathrm{w} / \mathrm{v}$ ) pretreatment of the mesocarp and seed of (TmfW).

\section{Statistical analysis}

The statistical software Design Expert 6.0.7. (Stat-Ease, Minneapolis, USA) was used for the design of experiments, regression, and graphical analysis of the data obtained and for statistical analysis of the model to evaluate the analysis of variance (ANOVA) and it was used also for the optimization of the bioethanol fermentation process.

\section{Validation of the model under the optimized conditions}

The optimum conditions obtained after the statistical optimization was used in bioethanol production to correlate the values obtained. The bioethanol yield and volumetric productivity were estimated as described in Equation 1.

\section{Result and Discussion}

\section{Reducing sugars present in the T. madagascariense}

T. madagascariense is known to be rich in carbohydrate (60\%) Adewuyi et al. (2015). The mesocarp and seeds contained about $17.1 \mathrm{~g} / \mathrm{L}$ and $11.2 \mathrm{~g} / \mathrm{L}$ of the total reducing sugar without pretreatment. The addition of cellulase to the clarified homogenate increased the reducing sugar to 33.2 and $39 \mathrm{~g} / \mathrm{L}$ in the mesocarp and seed, respectively (Fig. 1). This could be connected to the cellulose content of the seed and mesocarp that upon enzymatic digestion results in the release of soluble reducing sugars. There was not any significant $(\mathrm{p}<0.05)$ increase in the total reducing sugar concentration in both seed and mesocarp of T. madagascariense as the enzyme concentration increased from 5.0 to $10 \%(\mathrm{w} / \mathrm{v})$. This might be indicative of the complete digestion of the cellulose present in the mesocarp and seeds. 


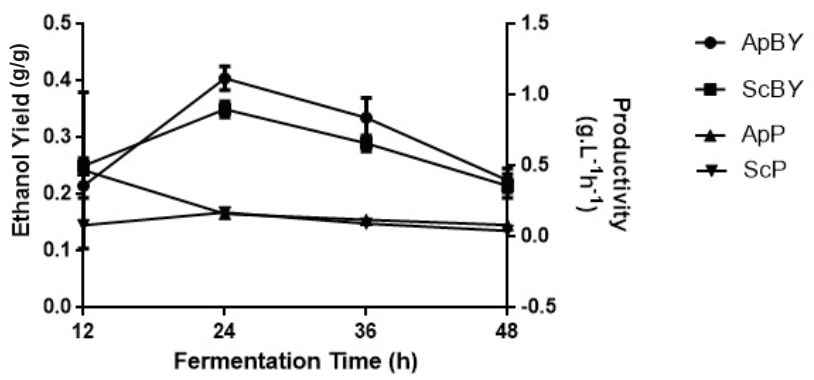

Figure 2. Bioethanol yield and volumetric productivity estimation by fermentation of the mesocarp of T. madagascariense fruit waste (Tmfw) using both A. pullulans and S. cerevisiae. ApBY and ScBY represent the bioethanol yield when $A$. pullulans and $S$. cerevisiae were used for the fermentation process while ApP and ScP represents the volumetric productivity when A. pullulans and S. cerevisiae were used for the fermentation of the mesocarp of (Tmfw).

\section{Fermentation of the clarified homogenate to bioethanol}

Depending on the yeast used for fermentation, the maximum ethanol yield $(\mathrm{g} / \mathrm{g})$ and \% ethanol yield varied accordingly. S. cerevisiae and A. pullulans fermented the clarified supernatant of the seed and mesocarp to optimally produce ethanol after $24 \mathrm{~h}$ (Fig. 2). Comparatively, A. pullulans had higher bioethanol yield and productivity than $S$. cerevisiae and this suggests that $A$. pullulans might be exploited industrially for bioethanol production as a useful alternative to $S$. cerevisiae. The decline in bioethanol production observed after $24 \mathrm{~h}$ might be due to the decrease in the total reducing sugars present for the microorganisms to act upon. The findings in this present

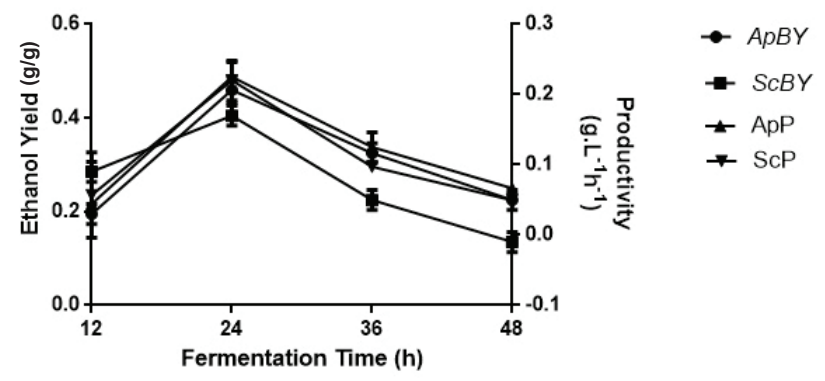

Figure 3. Bioethanol yield and volumetric productivity estimation by fermentation of the seeds of T. madagascariense fruit waste (Tmfw) using both $A$. pullulans and $S$. cerevisiae when $A$. pullulans and S. cerevisiae were used for the fermentation process while ApP and ScP represents the volumetric productivity when A. pullulans and S. cerevisiae were used for the fermentation of the seeds of (Tmfw).

study were akin to that observed by Betiku and Taiwo (2015) where the authors reported that it took $24 \mathrm{~h}$ for $S$. cerevisiae to ferment bread fruit hydrolysate for production of bioethanol.

\section{RSM optimization for bioethanol production and ANOVA analysis}

In the present study, seventeen independent experiments to evaluate bioethanol yield using the mesocarp of T. madagascariense fruit waste by considering the interactive effects of $\mathrm{pH}$, incubation time and substrate concentration. The observed and predicted bioethanol yield values are shown in Table 3 . The optimum condition for bioethanol production was $\mathrm{pH}$ of 5.95 , substrate

Table 3. ANOVA for response surface quadratic model.

\begin{tabular}{|c|c|c|c|c|c|}
\hline Source & Sum of squares $\left(\times 10^{-3}\right)$ & DF & F-value & Prob $>F$ & \\
\hline $\mathrm{pH}$ & 0.32 & 1 & 335.18 & $<0.0001$ & Significant \\
\hline Substrate & 0.03 & 1 & 230.49 & $<0.0001$ & Significant \\
\hline Time & 0.39 & 1 & 2.33 & 0.1706 & Not significant \\
\hline $\mathrm{pH} \times \mathrm{pH}$ & 0.39 & 1 & 28.41 & 0.0011 & Significant \\
\hline Substrate $\mathrm{x}$ substrate & 0.011 & 1 & 280.06 & $<0.0001$ & Significant \\
\hline Time $x$ time & 0.015 & 1 & 822.73 & $<0.0001$ & Significant \\
\hline $\mathrm{pH} \times$ substrate & 0.001 & 1 & 1116.84 & $<0.0001$ & Significant \\
\hline $\mathrm{pH} \times$ time & 4.029 & 1 & 0.088 & 0.7755 & Not significant \\
\hline Substrate $\mathrm{x}$ time & 0.11 & 1 & 291.26 & $<0.0001$ & Significant \\
\hline Model & 0.0470 & 9 & 212.86 & $<0.0001$ & Significant \\
\hline Residual & 0.1220 & 7 & & & \\
\hline Lack of fit & $2.48 \times 10-5$ & 3 & $1.92 \times 10-4$ & 1.0 & Not significant \\
\hline Pure error & 0.172 & 4 & & & \\
\hline $\mathrm{R} 2$ & 0.9964 & & & & \\
\hline Adj R2 & 0.9917 & & & & \\
\hline Pred R2 & 0.9943 & & & & \\
\hline Adeq precision & 41.370 & & & & \\
\hline C.V. & 0.8700 & & & & \\
\hline
\end{tabular}



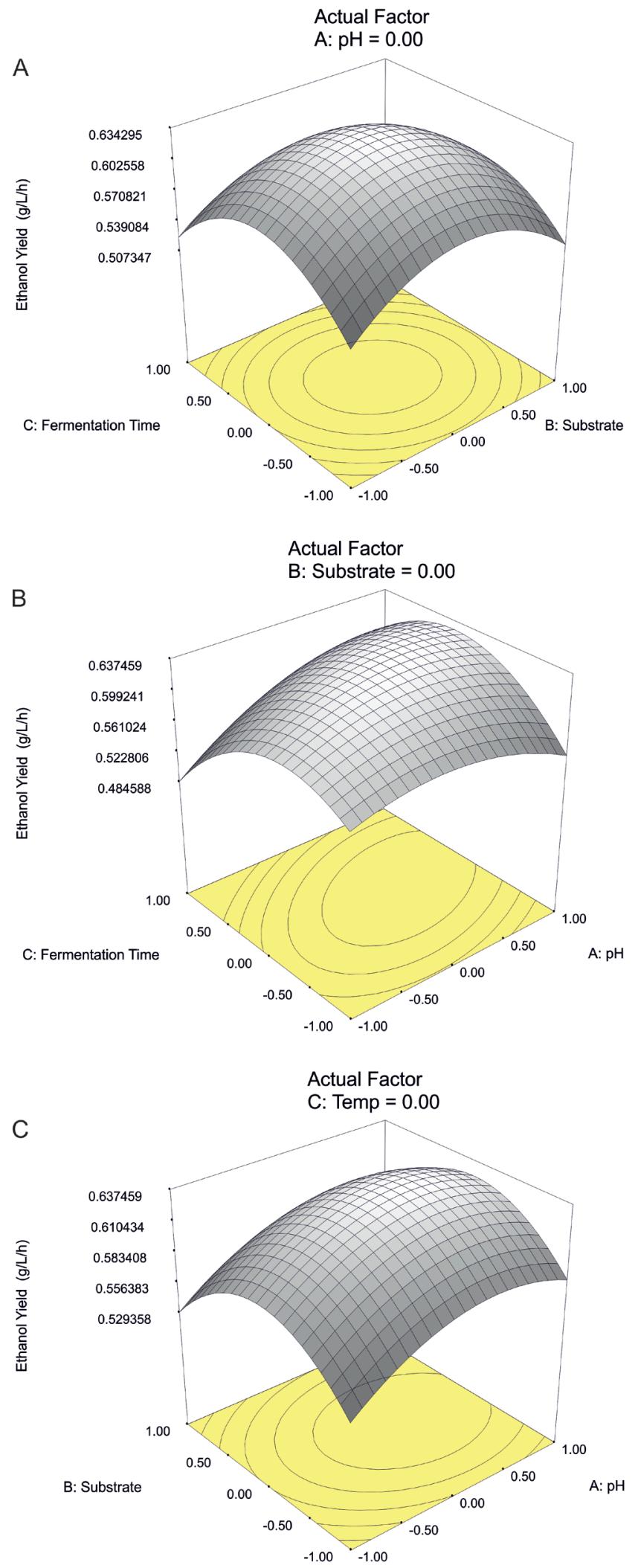

Figure 4. (A) Substrate vs $\mathrm{pH}$ with fermentation time held constant. (B) Fermentation time vs $\mathrm{pH}$ with substrate concentration held constant. (C) Fermentation time vs substrate with the $\mathrm{pH}$ held constant. concentration of $5.0 \mathrm{~g} / \mathrm{L}$ and incubation time of $24 \mathrm{~h}$. It is reported that optimum ethanol production occurs at a $\mathrm{pH}$ range of 4-6 and ethanol production is influenced by $\mathrm{pH}$ of the broth as it affects bacterial contamination, yeast growth, fermentation rate, and byproduct formation. From the ANOVA of the quadratic model, it was noted that model terms such as $\mathrm{pH}$, time, $\mathrm{pH} \times \mathrm{pH}$, substrate concentration $\mathrm{x}$ substrate concentration, time $\mathrm{x}$ time and $\mathrm{pH} \times$ time were significant $(\mathrm{p}<0.05)$. The model F-value of 212.9 implied that the model was significant. The F-value is often used as a measure of how the factors aptly describe the variation in the data set. The F-values obtained for the data set in this study indicates that the model is significant when also considering the $\mathrm{P}$-value $(<$ 0.0001). The quadratic model was used in the theoretical prediction of the bioethanol yield reliably due to the $\mathrm{R}^{2}$ value (Table 3 ). It is reported that the $\mathrm{R}^{2}$ values must fall between 0.75 and 0.80 for a good model fit. The values obtained in this study allows for the predictability of the bioethanol yield from the quadratic equation in coded factors as shown below (Equation 3):

$$
\begin{aligned}
\text { Ethanol Yield }= & +0.64+0.020 \times \mathrm{A}-2.008 \mathrm{E}-003 \times \mathrm{B}- \\
& 7.009 \mathrm{E}-003 \times \mathrm{C}-0.034 \times \mathrm{A}^{2}-0.056 \times \mathrm{B}^{2} \\
& -0.064 \times \mathrm{C}^{2}+5.512 \mathrm{E}-004 \times \mathrm{A} \times \mathrm{B}+0.032 \\
& \times \mathrm{A} \times \mathrm{C}-5.276 \mathrm{E}-003 \times \mathrm{B} \times \mathrm{C}
\end{aligned}
$$

where $\mathrm{A}, \mathrm{B}$, and $\mathrm{C}$ represent $\mathrm{pH}$, substrate concentration and time of fermentation, respectively.

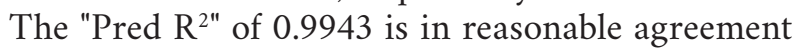
with the "Adj R ${ }^{2}$ of 0.9917."Adeq Precision" measures the signal to noise ratio. A ratio greater than 4 is desirable. The ratio of 41.371 obtained in this process indicates an adequate signal. The summary of the ANOVA analysis is shown in Table 4.

\section{Interaction between factors}

From the response surface plots (Fig. 3-5), it was deduced that there were moderate interactions between the variables considered in this study. To obtain these response surface curves, the interactions between two variables were investigated by obtaining $3 \mathrm{D}$ response surface plots while the third variable was kept constant. The optimum $\mathrm{pH}$ obtained was mildly acidic and increasing the $\mathrm{pH}$ resulted in a decrease in the bioethanol yield. The $\mathrm{pH}$ plays a crucial role in fermentation as it is directly tied to most biological processes (Manohar and Divakar 2005). Also, decreasing or increasing the fermentation period above $24 \mathrm{~h}$ resulted in a decline the bioethanol production. 


\section{Conclusion}

A readily available, cheap and non-toxic feedstock of $T$. madagascariense fruit wastes investigated in this study provides a novel source for bioethanol production. The reducing sugar present with and without enzymatic saccharification indicates that these agricultural wastes could be converted inexpensively to bioethanol. Validation of the model using the optimum conditions predicted after statistical optimization indicated that the volumetric productivity and bioethanol yield obtained was 0.24 $\mathrm{g} / \mathrm{L} / \mathrm{h}$ and $0.63 \mathrm{~g} / \mathrm{g}$, respectively.

\section{Acknowledgment}

The authors appreciate Mr. Tunde Oni, Department of Microbiology, Obafemi Awolowo University, Ile-Ife for providing useful technical assistance.

\section{References}

Ademakinwa AN, Agboola FK (2016) Biochemical characterization and kinetics of a purified yellow laccase from Aureobasidium pullulans (De Bary) isolated from soil containing decayed plant matter.J Genet Eng Biotechnol 14(1):143-151.

Ademakinwa AN, Ayinla ZA, Agboola FK (2017) Strain improvement and statistical optimization as a combined strategy for improving fructosyltransferase production by Aureobasidium pullulans NAC8.J Genet Eng Biotechnol 15(2):341-35.

Adewuyi A, Prasad BNR, Rao SK, Oderinde RA (2010) Oil composition, mineral nutrient and fatty acid distribution in the lipid classes of underutilized oils of Trilepisium madagascariense and Antiaris africana from Nigeria. Food Res Int 43:665-670.

Alma RD, Jorge AT, Ricardo AL (2015) Production of bioethanol from agro-industrial wastes. Fuel 149:85-89.
Betiku E, Taiwo AE (2015) Modelling and optimization of bioethanol production from breadfruit starch hydrolysate vis-à-vis response surface methodology and artificial neural network. Renew Energ 74:87-94.

Dash PK, Mohaptra S, Swain MR, Thatoi H (2017) Optimization of bioethanol production from saccharified sweet potato root flour by co-fermentation of Saccharomyces cerevisiae and Pichia sp. using OVAT and response surface methodologies. Acta Biol Szeged 61(1):13-23.

Joshi B, Bhatt MR, Sharma D, Joshi J, Malla R, Sreerama L (2011) Lignocellulosic ethanol production: Current practices and recent developments. Biotech Mol Biol Rev 6(8):172-182.

Lebaka (L)V (2013) Potential bioresources as future sources of biofuels production: An overview. In Gupta V, Tuohy M, eds, Biofuel Technologies. Springer, Berlin, Heidelberg.

Manohar B, Divakar S (2005) An artificial neural network analysis of porcine pancreas lipase catalysed esterification of anthranilic acid with methanol. Process Biochem 40(10):3372-3379.

Miller GL (1959) Use of dinitrosalicylic acid reagent for determination of reducing sugar. Anal Chem 31(3):426-428.

Nwamarah JU, Chikewendu JN, Otitoju GTO, Eme P (2015) Nutrients, anti-nutrients and phytochemical composition of Bosquiea angolensis fruits "Oze” consumed as snacks in Enugu State, Nigeria. Pak J Nutri 14(5):269-273.

Quadri HO, Ademakinwa NA, Adejumo AL, Agboola FK (2017) Partial purification and characterization of cellulolytic enzyme from Bacillus pantothenicus isolated from a dumpsite. Res Rev J Microbiol Biotechnol 6(2):4-11.

Razmovski R, Vucurovic V (2012) Bioethanol production from sugar beet molasses and thick juice using Saccharomyces cerevisiae immobilized on maize stem ground tissue. Fuel 92:1-8.

Sharma N, Sharma N (2018) Second generation bioethanol production from lignocellulosic wastes and its future perspective: A review. Int J Curr Microbiol Appl Sci 7(5):1285-1290. 